\title{
Pojav borove hržice (Thecodiplosis brachyntera) na Dleskovški planoti v 2016
}

\section{Nikica OGRIS $^{1 *}$, Maarten DE GROOT ${ }^{1}$}

V oktobru 2016 smo na Dleskovški planoti (Kamniško - Savinjske Alpe, GGO Nazarje) opazili povečan obseg poškodb rušja (Pinus mugo Turra) zaradi borove hržice ali borove muhe šiškarice, Thecodiplosis brachyntera (Schwagrichen 1835) (Diptera: Cecidomyiidae), sinonim Cecidomyia brachyntera Schwagrichen, 1835, angl. needle shortening gall midge.

\section{Razširjenost}

Pojavlja se po vsej Evropi (Gagné, 2010). Njena pogostost upada proti vzhodu. Najdena je bila tudi v osrednji Sibiriji. Prekomerne namnožitve so najpogosteje zabeležene prav v srednji Evropi. V Sloveniji jo je našel Janžič na rdečem boru (Pinus sylvestris L.) v letih 1976 in 1977 (Simova - Tošić in sod., 1996). O njej je že pisal tudi Titovšek (1993), ki jo omenja kot moteči dejavnik gozdnega drevja v Sloveniji.

\section{Gostitelji}

Vse vrste borov (Pinus), najpogosteje napada rušje in rdeči bor.

\section{Simptomi}

Borovi poganjki imajo letošnje iglice krajše in le-te so odebeljene pri osnovi (šiška). Vsak par iglic vsebuje majhno kamrico (slika 3), kjer se razvija ena ali več ličink oranžne barve. Navadno napada iglice vrhnjih poganjkov (slika 1 in 2). Napadene iglice porumenijo in prezgodaj odpadejo.

\section{Biologija}

Roji od maja (nižji predeli) do junija (višji predeli). Samica odlaga jajčece pod luske brstov ali pa neposredno v bazo nepopolno razvite iglice. Ličinka se razvija $\mathrm{v}$ osnovi iglice, ki se navadno odebeli. V kamrici je navadno ena ličinka, $v$ gradaciji pa tudi do sedem. Mlada ličinka je brezbarvna, starejša ličinka pa je značilno oranžne barve, brez glave, oči in brez nog (slika 4). Ličinka meri 2,2-2,7 $\times 0,7-1,0 \mathrm{~mm}$. Iglice ostanejo kratke, porumenijo in $v$ jeseni odpadejo. Odrasla ličinka prezimi v osnovi iglice. Spomladi se zabubi in nekoliko kasneje izletijo odrasle žuželke, velike 2,5-3 mm. Zadek odraslih žuželk je oranžen, oprsje in noge rjavordeče, samica je večja od samca. Tipalke so črne, sestavljene iz 12 členkov, baza tipalke pa ima še dodatna dva členka. Krila imajo tri žile, kakor je pravilo za družino hržic (Cecidomyiidae). Samci imajo podaljšan zadek, samica ima dolgo leglico. Razvije eno generacijo na leto (Gradojević, 1925). Z raziskavo so ugotovili, da dolgoročna fluktuacija gostote populacije borove hržice korelira $\mathrm{z}$ dolgoročnimi fluktuacijami temperature (Csóka in sod., 1997).

\section{Vpliv}

Borova hržica je pomemben škodljivec vseh vrst borov v srednji Evropi, kjer je bilo zabeleženih že več izbruhov v 19. in 20. stoletju. T. brachyntera lahko pomembno zmanjša primarno produkcijo napadenega drevesa. Vpliv na napadeno drevo je odvisen od trajanja namnožitve in število iglic, ki ostane na poganjkih po napadu. Močneje poškodovana drevesa postanejo manj vitalna in bolj dovzetna na fakultativne parazite in sekundarne škodljivce. Raziskava na Švedskem je ugotovila, da se letni prirastek lesa rdečega bora $\mathrm{z}$ visoko intenziteto poškodb ( $71 \%$ defoliacija) ni razlikoval od srednje intenzitete poškodb (26\% defoliacija). Zaznali pa so krajše poganjke na zelo poškodovanih borih in sicer eno leto po defoliaciji (Glynn in Lindelöw, 2002).

\section{Parazitoidi}

Najpogostejša parazitoida borove hržice sta iz skupine kožekrilcev (Hymenoptera): Platygaster compressicornis in Aprostocetus micantulus, manj pogosta pa sta Pseudencyrtus idmon in Torymus heyeri (Skuhravý in Thuróczy, 2007).

\section{Možne zamenjave}

Poškodbe zaradi borove hržice lahko zamenjamo s sušico najmlajših borovih poganjkov (Diplodia pinea (Desm.) J. Kickx f.), saj oba škodljiva dejavnika povzročata nastanek krajših iglic na koncu poganjka. Razlikovalni znak je prisotnost oranžne ličinke v bazi iglice, kar je znak za borovo hržico, in črnih piknidijih (nespolna trosišča) na odmrlih iglicah in odmrlih poganjkih, kar je najpomembnejši znak za sušico najmlajših borovih poganjkov.

\section{Zanimivost}

Borova hržica lahko prenaša sušico borovih vej, ki jo povzroča gliva Cenangium ferruginosum Fr. (Jurc in sod., 2000).

\section{Viri}

Csóka G., Mattson W. J., Stone G. N., Price P. W. 1997. The biology of gall-inducing arthropods. North Central Research Station, Forest Service, USDA. General Technical Report, NC - 199: 329 str.

Gagné R. J. 2010. A Catalog of the Cecidomyiidae (Diptera) of the World. Washington, DC, USA. Systematic Entomology Laboratory, Agricultural Research Service, U.S. Department of Agriculture: 544 str.

Glynn C., Lindelöw Å. 2002. Defoliation by the needle-shortening pine gall midge, Thecodiplosis brachyntera, on pines in Central Sweden. Scandinavian Journal of Forest Research, 17 (2): 150-157 Gradojević M. 1925. Thecodiplosis brachyntera Schwaer., škudce borbych lesu na Slovensku. Šmarski list, 49 (3): 196-197

Jurc D., Jurc M. Sieber, T. N., Bojović, S. 2000. Endophytic Cenangium ferruginosum (Ascomycota) as a reservoir for an epidemic of Cenangium dieback in Austrian Pine. Phyton, 40 (4): 103-108 
Simova - Tošić D., Skuhravá M., Skuhravý V. 1996. Gall midges (Diptera: Cecidomyiidae) of Slovenia. Scopolia, 36: 1-23

Skuhravý V., Thuróczy C. 2007. Parasitic Hymenoptera associated with Thecodiplosis brachyntera (Diptera: Cecidomyiidae) on the genus Pinus (Pinaceae) in the Czech Republic. Journal of Forest Science, 53 (8): 381-389

Titovšek J. 1993. Pršice in žuželke - moteči dejavniki na gozdne drevju v Sloveniji. Zbornik gozdarstva in lesarstva, 42: 67-84

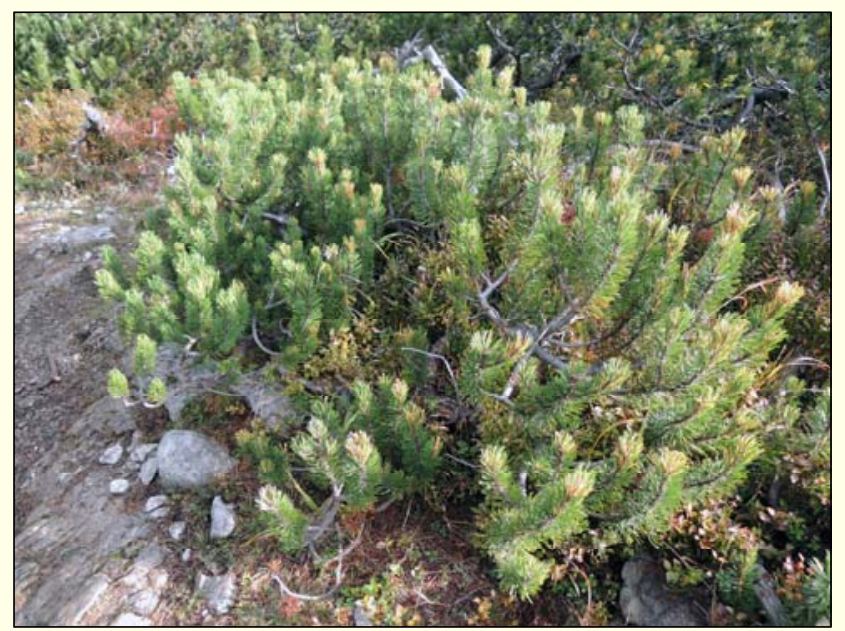

Slika 1: Grm rušja je poškodovala borova hržica (Thecodiplosis brachyntera) (Foto: N. Ogris)

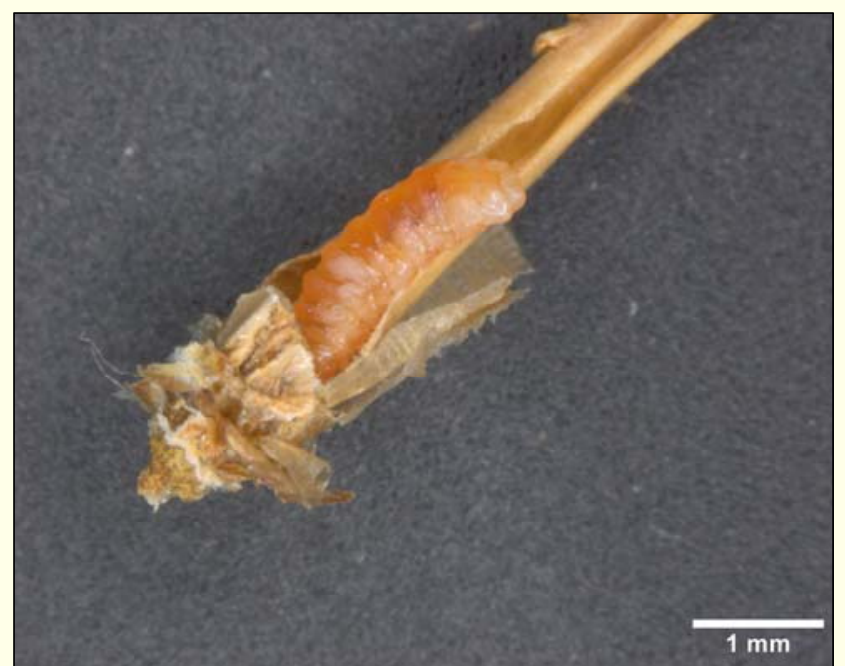

Slika 3: Ličinka borove hržice (Thecodiplosis brachyntera) se prehranjuje v osnovi iglice (Foto: N. Ogris)
${ }^{1}$ Gozdarski inštitut Slovenije, Večna pot 2, 1000 Ljubljana *nikica.ogris@gozdis.si

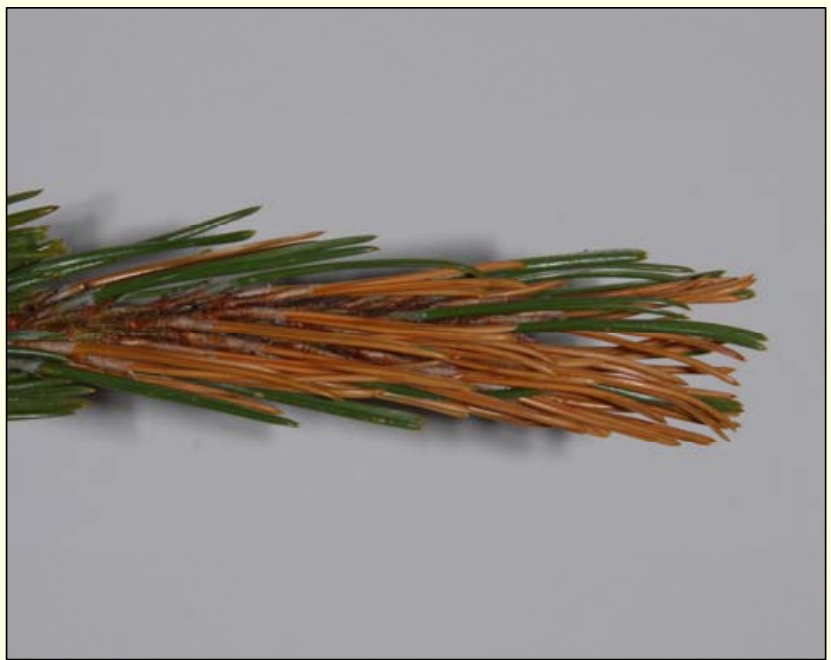

Slika 2: Poškodovane iglice zaradi borove hržice (Thecodiplosis brachyntera) (Foto: N. Ogris)

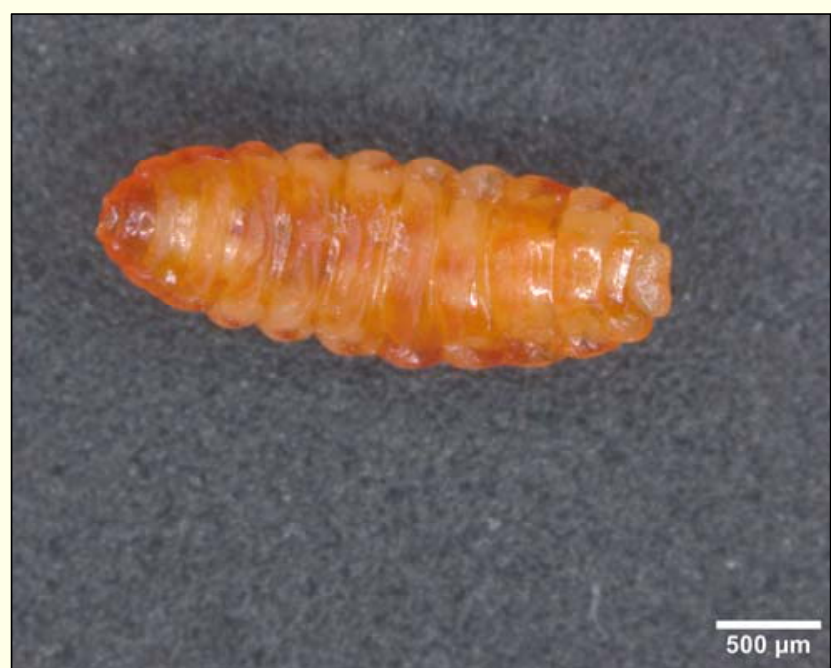

Slika 4: Ličinka borove hržice (Thecodiplosis brachyntera) (Foto: N. Ogris 